\title{
Predicting vegetation-stabilized dune field morphology
}

\author{
Thomas E. Barchyn ${ }^{1}$ and Chris H. Hugenholtz ${ }^{1,2}$ \\ Received 27 June 2012; revised 30 July 2012; accepted 1 August 2012; published 12 September 2012.
}

[1] The morphology of vegetation-stabilized dune fields on the North American Great Plains (NAGP) mostly comprises parabolic dunes; stabilized barchan and transverse dunes are rare, with the exception of transverse and barchan megadunes in the Nebraska Sand Hills. We present a hypothesis from a numerical dune field model explaining the vegetationstabilized morphology of dunes under unidirectional wind. Simulations with a range of initial dune morphologies (closelyspaced transverse to disperse barchans) indicate that stabilized morphology is determined by the ratio of slipface deposition rate to deposition tolerance of vegetation. Slipface deposition rate is related to dune height, flux, and celerity. With a fixed depositional tolerance, large, slow-moving dunes have low slipface deposition rates and 'freeze' in place once vegetation is introduced. Relatively small, fast dunes have high slipface deposition rates and evolve into parabolic dunes, often colliding during stabilization. Our hypothesis could explain differences in stabilized morphology across the NAGP and elsewhere. Citation: Barchyn, T. E., and C. H. Hugenholtz (2012), Predicting vegetation-stabilized dune field morphology, Geophys. Res. Lett., 39, L17403, doi:10.1029/2012GL052905.

\section{Introduction}

[2] The interplay between vegetation growth and aeolian sand transport on dunes produces a range of outcomes, ranging in scale from the development of parabolic [Gaylord and Stetler, 1994; Tsoar and Blumberg, 2002; Durán and Herrmann, 2006; Wolfe and Hugenholtz, 2009] to nebkha dunes [Ardon et al., 2009]. In the North American Great Plains, where the majority of dunes are stabilized by vegetation, the most pervasive dune morphology is parabolic [cf. Hugenholtz and Wolfe, 2005; Schmeisser et al., 2010]. However, in a small number of dune fields, such as the Nebraska Sand Hills - the largest contiguous dune field in the Great Plains - the most common forms of vegetationstabilized dunes are barchan and transverse mega-dunes [Stokes and Swinehart, 1997]. Additionally, in some dune fields, such as the northern section of the Great Sand Hills of Saskatchewan, Canada, the vegetation-stabilized dune morphology is hummocky, whereby individual dunes are

\footnotetext{
${ }^{1}$ Department of Geography, University of Lethbridge, Lethbridge, Alberta, Canada.

${ }^{2}$ Faculty of Environmental Design, University of Calgary, Calgary, Alberta, Canada.

Corresponding author: T. E. Barchyn, Department of Geography, University of Lethbridge, 4401 University Dr., Lethbridge, AB T1K 3M4, Canada. (tom.barchyn@uleth.ca)

C2012. American Geophysical Union. All Rights Reserved. 0094-8276/12/2012GL052905
}

indistinguishable. The specific mechanism leading to such marked differences in stabilized dune field morphology is unclear, confounding understanding of former dune morphodynamics in stabilized settings such as the NAGP, and limiting our capacity to forecast morphodynamic trajectories of dune fields currently or potentially influenced by vegetation.

[3] The presence of vegetation in dune environments begins to modify dune morphology in a manner that is a direct manifestation of the relative kinematics of vegetation growth and sediment transport [Baas and Nield, 2007]. There is evidence to suggest that vegetation-dune interactions are relatively universal and can be treated in a simplified manner. For example, active and stabilized parabolic dunes in coastal and inland locations (including a broad range of climate zones and vegetation) show remarkably similar morphology. Simple numerical models have demonstrated that parabolic dunes can be modeled with only a few parameters: (i) an initial sand deposit or dune, and (ii) vegetation growth that responds to topographic change and regulates (iii) aeolian sediment transport [e.g., Durán and Herrmann, 2006; Baas and Nield, 2007; Barchyn and Hugenholtz, 2012].

[4] The behavior of bare dunes during vegetation encroachment is important for resolving potential morphodynamic responses under climate changes [e.g., Wolfe and Hugenholtz, 2009]. Using a numerical model, Durán and Herrmann [2006] predicted conditions responsible for the barchanparabolic transition with a 'fixation index' $(\theta)$, where $\theta=$ $Q /\left(V^{1 / 3} V_{v}\right), Q$ is sediment flux, $V$ is barchan volume, and $V_{v}$ is vertical vegetation growth rate. Durán and Herrmann [2006] identified a threshold in the model behavior where $\theta=0.5$. When $\theta>0.5, Q$ out-competes $V_{v}$ and the barchan retains its form and mobility; when $\theta<0.5$ the dune stabilizes as parabolic. Elongation of parabolic arms increases as $\theta \rightarrow 0.5$. This model, while promising for predicting the barchan-parabolic transition [Reitz et al., 2010], has some limitations. The threshold $(\theta=0.5)$ is configured for the stabilization of isolated barchan dunes with classical barchan morphology; this only applies to environments with relatively low quantities of sediment. Further, its application is unproven for explaining the stabilized morphology of dune fields, which contain many different morphologies and spacings of dunes.

[5] Here, we present a new hypothesis stemming from a numerical dune field model that explains variations in the vegetation-stabilized morphology of dune fields formed in uni-directional wind regimes. This study is a component of a larger project aimed at understanding and quantifying dune stabilization and activation worldwide. Our previous results [Barchyn and Hugenholtz, 2012] indicated that the dune field stabilization time can be predicted as an approximate linear function of the ratio of deposition rate and deposition tolerance of vegetation. Here, we expand on these results by describing and classifying the resultant dune field morphology, allowing 
us to propose a hypothesis for the morphology of stabilized dunes on the NAGP.

\section{Model Algorithm and Simulations}

[6] We use the numerical model and simulation structure of Barchyn and Hugenholtz [2012]. The model operates with a non-dimensional spatial scale normalized to the peak deposition tolerance of vegetation $\left(V_{\text {peak }}\right)$. The model space consists of three arrays: surface height $(H)$, non-erodible basement height ( $B$; unchanging at 0$)$, and vegetation effectiveness $(V)$. Vegetation effectiveness is scaled to the vegetation cover that completely eliminates transport: at $V=1$ sediment transport $(Q)=0$, linking with efforts to relate vegetation cover and $Q$ [e.g., Lancaster and Baas, 1998]. Vegetation is limited to the range $0-4$. Model space was 100 by 200 cells, long axis downwind, with periodic boundaries. Wind shear stress was constant $(\tau=1)$ from the west, except in lee shadow zones where $\tau=0$ [cf. Werner, 1995], simulating the airflow separation zone [Frank and Kocurek, 1996]. The model picks a random location in the model space and calculates $Q$ from the maximum saturated sediment flux $\left(Q_{\max }=0.1\right)$ and fetch saturation distance $\left(D_{\text {fetch }}=\right.$ 10 cells) with $Q=\Sigma\left(\tau_{i, j}-V_{i, j}\right) Q_{\max } / D_{\text {fetch }}$ in a 'while' loop that runs from the target cell upwind until one of three conditions is met: (i) $\left(\tau_{i, j}-V_{i, j}\right) \leq 0$ (complete transport cutoff), (ii) $H_{i, j}=0$ (no sediment available), or (iii) distance upwind $=$ $D_{\text {fetch }}$. Subscript $i$ and $j$ denote local coordinates. With this algorithm sediment transport is reduced immediately downwind from boundaries in the model space, simulating the empirically measured fetch effect [Delgado-Fernandez, 2010; see also Barchyn and Hugenholtz, 2012]. Following this, the model moves $Q$ sediment 1 cell downwind and an avalanche routine ensures no cell has a slope greater than the angle of repose $\left(34^{\circ}\right)$ with the 4 cardinal neighbours. If the angle of repose is exceeded, the model moves sediment from the higher to lower cell. With equal slopes that exceed repose one direction is picked randomly. One iteration $=20,000$ transport events; one year $=100$ iterations.

[7] Vegetation change is controlled by the topographic change at a site over the previous year (see growth curve: Figure S1 of the auxiliary material). ${ }^{1}$ The growth curve is developed qualitatively from descriptions of vegetation response to topographic change and closely follows previous efforts [Durán and Herrmann, 2006; Baas and Nield, 2007]. For many pioneer dune species growth is stimulated under deposition up to a critical value $\left(V_{\text {peak }}\right)$, at which vegetation can no longer out-compete sediment deposition and cannot survive [Maun and Perumal, 1999; see Barchyn and Hugenholtz, 2012]. The growth curve specifies four zones of vegetation change (see Figure S1 of the auxiliary material): (i) extreme erosion: all vegetation removed, (ii) minor erosion: vegetation slowly dies, (iii) minor deposition: vegetation grows at maximum rate, and (iv) extreme deposition: all vegetation is buried [Maun, 1998; Maun and Perumal, 1999]. If deposition $>V_{\text {peak }}$ mid-year: $V_{i, j}=0$, simulating an advancing slipface.

[8] Before introducing vegetation, we simulated a spectrum of different initial unvegetated dune morphologies, sizes and spacings. By varying the initial sediment thickness

\footnotetext{
${ }^{1}$ Auxiliary materials are available in the HTML. doi:10.1029/ 2012GL052905
}

$(0.5-2.75$, intervals of 0.25$)$ and unvegetated growth time of dunes (5-75 years, intervals of 5 years), we generated 150 unique dune fields (from relatively small dispersed barchans to large transverse dunes) (see further in Barchyn and Hugenholtz [2012]). This is different from the approach of Durán and Herrmann [2006], which examined the effect of vegetation growth on a single, idealized barchan dune. We simulate different geomorphologies to link with our case example of dune stabilization on the North American Great Plains - which we assume began with different dune field geomorphologies and was subject to an approximately constant climate shift (and vegetation growth characteristics). Results are examined in terms of the deposition rate / $V_{\text {peak }}$ ratio, which is applicable to a real dune field with arbitrary morphology.

[9] Prior to stabilizing the dune field we assessed the deposition rate distribution. We subset deposition cells from differenced topography (over 1 year) at the instant vegetation was introduced. Deposition rate is a kinematic measurement applicable across all real dune forms (from isolated barchan to closely-spaced transverse) without explicit consideration of dune form. During stabilization we tracked the morphology of each dune field at yearly intervals and evaluated the final stabilized dune morphology. Vegetation and sediment transport parameters (climate) were held constant during stabilization. We classified stabilized dune fields into 3 classes: (i) transverse/barchan: the majority of dunes did not trail arms or invert shape into parabolic morphology, dunes tended to stabilize in situ, (ii) parabolic: parabolic dunes formed and stabilized with recognizable parabolic morphology, and (iii) collision: parabolic dunes formed and stabilized through collisions yielding a hummocky stabilized topography. This topography is the result of highly elongate parabolic dunes forming in closely-spaced dune fields. Trailing ridges associated with the migration of parabolic dunes are present; however, discernible parabolic heads are frequently indistinguishable. We consider collisions as any situation where a dune over-rides part of another dune. Classes should be considered as a continuum of dune field morphologies; we classify here for the purposes of description (Figure 1 Figure 2, Animations S1-S3 of the auxiliary material).

\section{Results}

[10] Introduction of vegetation resulted in complete stabilization of all dune fields. Dunes changed morphology and often collided during stabilization. Vegetation first stabilized interdune areas. On dunes, vegetation spread from crest terminations, anchoring the lateral margins and, in some cases, allowing a parabolic head to advance downwind (Figure 2, Animations S1-S3 of the auxiliary material). Depositional environments were either (i) unvegetated: sediment transport outcompeted vegetation growth and the dune advanced downwind (e.g., deposition rate $>V_{\text {peak }}$ ), or (ii) vegetated: vegetation outcompeted sediment transport and grew on the slipface and upper crest (e.g., deposition rate $<V_{\text {peak }}$ ). Since vegetation growth parameters were constant, different behaviours were the result of different dune field geomorphologies. Dichotomous behavior (vegetated / not vegetated) in deposition environments was observed throughout all simulations and largely controlled whether a wind-parallel section of a dune would trend towards stabilization. 

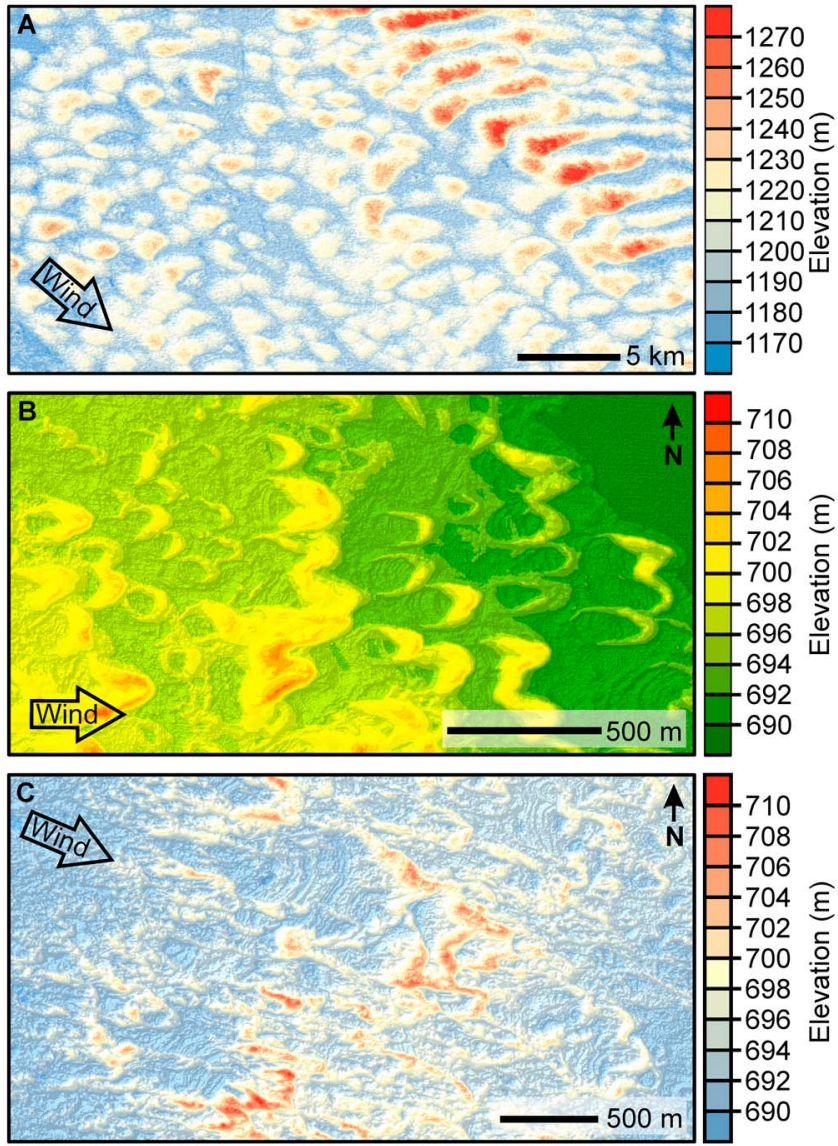

Figure 1. Samples of different stabilized dune morphology. (a) Stabilized mega-barchans in the Nebraska Sand Hills $\left(42.1760^{\circ} \mathrm{N}, 102.1940^{\circ} \mathrm{W}\right.$; from ASTER-GDEM). (b) Stabilized parabolic dunes in Saskatchewan, Canada [see Wolfe and Hugenholtz, 2009] $\left(50.1825^{\circ} \mathrm{N}, 109.1658^{\circ} \mathrm{W}\right)$. (c) Stabilized parabolic dunes in Saskatchewan, Canada that show hummocky topography $\left(50.6180^{\circ} \mathrm{N}, 109.2311^{\circ} \mathrm{W}\right)$. Each image is real sample of the three descriptive classes of stabilized morphology: (i) transverse/barchan (Figure 1a), (ii) parabolic (Figure 1b), and (iii) collision (Figure 1c).

[11] For widely-spaced barchans with low height and high celerity, stabilization progressed slowly because initial deposition rates were greater than $V_{\text {peak }}$, allowing the dunes to develop long trailing arms where vegetation anchored dune margins, while the central portions continued advancing downwind (Figures $2 \mathrm{a}$ and $2 \mathrm{~b}$, Animations S1 and S2 of the auxiliary material). Contrarily, relatively large, closelyspaced transverse dunes stabilized rapidly because slipface deposition rates were below $V_{\text {peak }}$; this preserved most of the original, unvegetated morphology (Figure 2c, Animation S3 of the auxiliary material). Parabolic dunes that extended long trailing arms tended to stabilize through collisions and yielded hummocky topography (Figure 2b, Animation S2 of the auxiliary material). Although the dunes stabilized through formation of parabolic dunes, the end result is not discernible as remnant parabolic forms.

[12] Deposition rate / $V_{\text {peak }}$ distributions qualitatively echoed above observations (Figure 3). Simulations that stabilized with the transverse/barchan morphology showed unvegetated deposition rates predominantly below $V_{\text {peak }}$. These dunes were relatively tall, slow, and better organized. Parabolic and collision morphologies showed (i) a wider spread in distribution, and (ii) higher values. Many deposition environments in these simulations had deposition rates that exceeded $V_{\text {peak }}$ and could advance downwind without hosting vegetation. The high proportion of small values $(<0.5)$ in these simulations is due to dune fields that were poorly organized (more variability in dune height and celerity, see Figure 2b1), and/or wider-spaced (with wind-parallel barchan arms with low deposition rates, see Figure 2a1). Further statistics of our simulated dune field geomorphologies are in Supplementary information linked with Barchyn and Hugenholtz [2012]. In effect, Figure 3 shows the relative proportion of deposition environments that supported vegetation within simulated dune fields.

\section{Discussion}

[13] Our simulations reveal two distinct behaviors: (i) parabolic dunes formed from relatively small, widely-spaced barchan and transverse dunes, or (ii) relatively large barchan and transverse dunes vegetated in situ. Although crest vegetation contributed, the dominant control of whether a dune advanced downwind (parabolic and collision classes), or vegetated in place (barchan/transverse class) was the ratio of slipface deposition rate / $V_{\text {peak }}$.

[14] Slipfaces vegetate first because the growth curve (see Figure S1 of the auxiliary material) is weighted to grow vegetation only in regions of deposition. This has been documented for real parabolic dunes [Pye, 1982; Durán et al., 2008; Hugenholtz, 2010], and is consistent with biological research [Maun, 1998; Maun and Perumal, 1999].

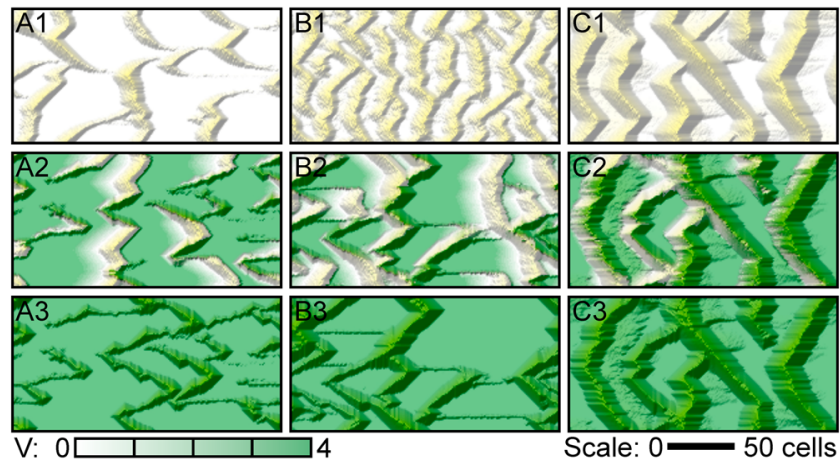

Figure 2. Representative examples of simulations showing dune morphology prior to the introduction of vegetation, during stabilization, and final stabilized morphology. (a) Parabolic dune stabilization: A1 (0 yrs), A2 (25 yrs), A3 (77 yrs) (initial sediment thickness $=0.5$, pre-stabilization growth time $=75 \mathrm{yrs}$, see also 2012GL052325-ms01.mpg). (b) Collision dune stabilization: B1 (0 yrs), B2 (36 yrs), B3 (84 yrs) (initial sediment thickness $=1.0$, pre-stabilization growth time $=15 \mathrm{yrs}$, see also 2012GL052325-ms01.mpg). (c) Transverse/barchan dune stabilization: $\mathrm{C} 1$ ( 0 yrs $), \mathrm{C} 2$ (16 yrs), C3 (43 yrs) (initial sediment thickness $=2.75$, pre-stabilization growth time $=75 \mathrm{yrs}$, see also 2012GL052325ms01.mpg). 


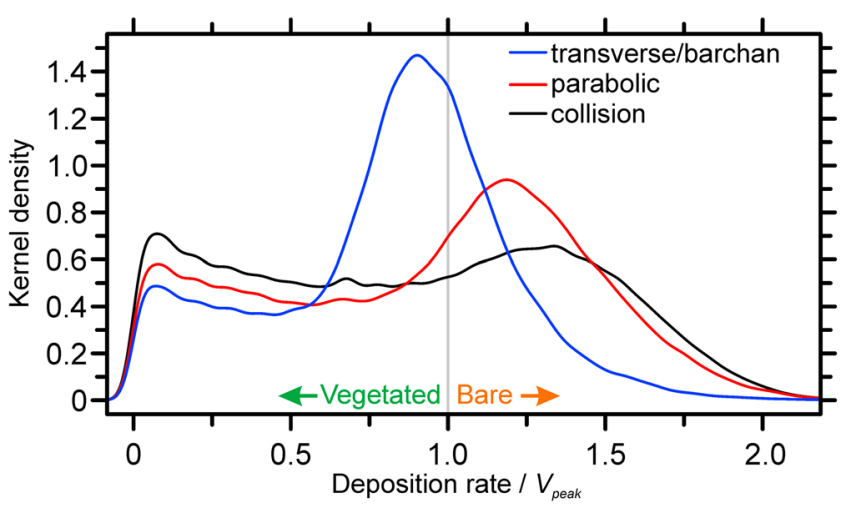

Figure 3. Kernel density of the ratio of deposition rate to peak deposition tolerance of vegetation $\left(V_{\text {peak }}\right)$ pre-stabilization. The three curves show each class of stabilized morphology: (i) transverse/barchan: dunes stabilized in situ $(n=$ 255467), (ii) parabolic: dunes stabilized as parabolic dunes $(n=131898)$, and iii) collision: dunes stabilized as parabolic dunes with collisions yielding hummocky topography $(n=469728)$. Kernel density bandwidth $=0.03$.

When the sediment transport rate across the dune brink is constant, smaller dunes advance downwind faster than larger dunes. Recall that the downwind advance of a dune (celerity) is proportional to $q / s_{h}$, where $q$ is flux and $s_{h}$ is slipface height. Thus, for a given cross-brink $q$ and slipface geometry, slipface deposition rate decreases as $s_{h}$ increases due to a larger slipface area. The lower the deposition rate, the less likely it will exceed $V_{\text {peak }}$. If deposition on a slipface cannot exceed $V_{\text {peak }}$ (Zone (iii) in Figure S1 of the auxiliary material), vegetation expands, stabilizes the slipface, and quickly spreads to the crest and stoss slope.

[15] The quantitative framework of measuring the ratio between deposition rate and $V_{\text {peak }}$ also functions intuitively. Outside the bounds of our simulation set, if the ratio $\ll 1$, we would expect dune fields to 'freeze' in place as nearly all deposition environments would host vegetation. Similarly, if deposition rates were dominantly above $V_{\text {peak }}$, we would expect barchan and transverse dunes to maintain unvegetated form [e.g., Durán and Herrmann, 2006]. No vegetation would be able to colonize the crest terminations and induce differential stabilization and arm shear responsible for parabolic dune formation. In effect, the formation of parabolic dunes requires a distribution of deposition rates that spans $V_{\text {peak }}$.

[16] Dune-dune collisions are an important stabilizing mechanism. Simulations of single barchan dunes [e.g., Durán and Herrmann, 2006] are difficult to apply to real dune fields as highly elongate parabolic forms will inevitably collide with another dune during stabilization (Figure 1c). Collisions have two effects: (i) dunes stabilize pre-maturely due to rapid slipface height increase, and (ii) stabilization produces hummocky remnant topography. This hummocky topography is difficult to interpret because there are few discernible remnant dunes, although our simulations suggest it is the direct product of collision-dominated stabilization. Hummocky topography has not previously been discussed as a result of collision-dominated stabilization [see also Barchyn and Hugenholtz, 2012].
[17] Our results suggest that one explanation for the stabilized barchan and transverse mega-dunes in the Nebraska Sand Hills is that they were simply too large, and consequently too slow to out-compete vegetation colonization. We expect that, during stabilization of the Nebraska Sand Hills, deposition rates $\ll V_{\text {peak }}$. In other dune fields throughout the Great Plains, parabolic dunes dominate the stabilized morphology because the unvegetated dunes, whether barchan or transverse, were relatively much smaller, leading to high slipface deposition rates relative to $V_{\text {peak }}$. Overall, our hypothesis of comparing distributions of deposition rates to $V_{\text {peak }}$ could provide a powerful and generally applicable tool to explore variability in stabilized dune field morphology worldwide - both as a predictor of future dune morphology - and as an indicator of the relative balance between transport and vegetation growth in paleo-stabilized dunes.

[18] Acknowledgments. This research was supported by the National Sciences and Engineering Research Council of Canada, Alberta Innovates, Cenovus Energy, and computing resources from WestGrid and Compute/ Calcul Canada. ASTER-GDEM is a product of METI and NASA. We acknowledge the helpful comments of two anonymous reviewers and Editor Paolo D'Odorico.

[19] The Editor thanks Nick Lancaster and an anonymous reviewer.

\section{References}

Ardon, K., H. Tsoar, and D. G. Blumberg (2009), Dynamics of nebkhas superimposed on a parabolic dune and their effect on the dune dynamics, J. Arid Environ., 73, 1014-1022, doi:10.1016/j.jaridenv.2009.04.021.

Baas, A. C. W., and J. M. Nield (2007), Modelling vegetated dune landscapes, Geophys. Res. Lett., 34, L06405, doi:10.1029/2006GL029152.

Barchyn, T. E., and C. H. Hugenholtz (2012), Aeolian dune field geomorphology modulates the stabilization rate imposed by climate, J. Geophys. Res., 117, F02035, doi:10.1029/2011JF002274.

Delgado-Fernandez, I. (2010), A review of the application of the fetch effect to modelling sand supply to coastal foredunes, Aeolian Res., 2, 61-70, doi:10.1016/j.aeolia.2010.04.001.

Durán, O., and H. J. Herrmann (2006), Vegetation against dune mobility, Phys. Rev. Lett., 97, 188001, doi:10.1103/PhysRevLett.97.188001.

Durán, O., M. V. N. Silva, L. J. C. Bezerra, H. J. Herrmann, and L. P. Maia (2008), Measurements and numerical simulations of the degree of activity and vegetation cover on parabolic dunes in north-eastern Brazil, Geomorphology, 102, 460-471, doi:10.1016/j.geomorph.2008.05.011.

Frank, A., and G. Kocurek (1996), Toward a model for airflow on the lee side of aeolian dunes, Sedimentology, 43, 451-458, doi:10.1046/j.13653091.1996.d01-20.x.

Gaylord, D. R., and L. D. Stetler (1994), Aeolian-climatic thresholds and sand dunes at the Hanford site, south-central Washington, U.S.A, J. Arid Environ., 28, 95-116, doi:10.1016/S0140-1963(05)80041-2.

Hugenholtz, C. H. (2010), Topographic changes of a supply-limited inland parabolic sand dune during the incipient phase of stabilization, Earth Surf. Processes Landforms, 35, 1674-1681, doi:10.1002/esp.2053.

Hugenholtz, C. H., and S. A. Wolfe (2005), Recent stabilization of active sand dunes on the Canadian prairies and relation to recent climate variations, Geomorphology, 68, 131-147, doi:10.1016/j.geomorph.2004.04.009.

Lancaster, N., and A. Baas (1998), Influence of vegetation cover on sand transport by wind: Field studies at Owens Lake, California, Earth Surf. Processes Landforms, 23, 69-82, doi:10.1002/(SICI)1096-9837(199801)23:1<69:: AID-ESP823>3.0.CO;2-G.

Maun, M. A. (1998), Adaptations of plants to burial in coastal sand dunes, Can. J. Bot., 76, 713-738, doi:10.1139/b98-058.

Maun, M. A., and J. Perumal (1999), Zonation of vegetation on lacustrine coastal dunes: Effects of burial by sand, Ecol. Lett., 2, 14-18, doi:10.1046/j.1461-0248.1999.21048.x.

Pye, K. (1982), Morphological development of coastal dunes in a humid tropical environment, Cape Bedford and Cape Flattery, North Queensland, Geogr. Ann., 64, 213-227, doi:10.2307/520647.

Reitz, M. D., D. J. Jerolmack, R. C. Ewing, and R. L. Martin (2010), Barchan-parabolic dune pattern transition from vegetation stability threshold, Geophys. Res. Lett., 37, L19402, doi:10.1029/2010GL044957.

Schmeisser, R. L., D. B. Loope, and J. A. Mason (2010), Modern and late Holocene wind regimes over the Great Plains (central U.S.A.), Quat. Sci. Rev., 29, 554-566, doi:10.1016/j.quascirev.2009.11.003. 
Stokes, S., and J. B. Swinehart (1997), Middle- and late-Holocene dune reactivation in the Nebraska sand Hills, USA, Holocene, 7, 263-272, doi:10.1177/095968369700700302.

Tsoar, H., and D. G. Blumberg (2002), Formation of parabolic dunes from barchan and transverse dunes along Israel's Mediterranean Coast, Earth Surf. Processes Landforms, 27, 1147-1161, doi:10.1002/esp.417.
Werner, B. T. (1995), Eolian dunes: Computer simulations and attractor interpretation, Geology, 23, 1107-1110, doi:10.1130/0091-7613(1995) $023<1107$ :EDCSAA $>2.3$. CO; 2 .

Wolfe, S. A., and C. H. Hugenholtz (2009), Barchan dunes stabilized under recent climate warming on the northern Great Plains, Geology, 37, 10391042, doi:10.1130/G30334A.1. 
Reproduced with permission of the copyright owner. Further reproduction prohibited without permission. 